\title{
Processing-induced changes in total phenolics and procyanidins in clingstone peaches
}

\author{
Danny K Asami, Yun-Jeong Hong, Diane M Barrett and Alyson E Mitchell* \\ Department of Food Science and Technology, University of California, Davis, CA 95616, USA
}

\begin{abstract}
Clingstone peaches contain a wide array of complex secondary plant metabolites and polyphenolics, and increasing evidence indicates that many of these components are important in human health. Oligomeric flavan-3-ol metabolites (procyanidins) are particularly interesting owing to their potent antioxidant activity and protective cardiovascular effects. To date, little information is available on how postharvest and processing conditions impact levels of phenolics and procyanidins in fruit. This research addresses the impact of lye peeling, freezing, storage temperature $\left(4\right.$ and $\left.30^{\circ} \mathrm{C}\right)$ and three different time-temperature sterilisation combinations on levels of total phenolics (TPs) in Ross clingstone peaches. Additionally, we describe the profile of procyanidin oligomers (monomers through heptamers) in clingstone and freestone peaches and demonstrate a dramatic decrease in procyanidins in thermally processed peaches. TP levels ranged between 316 and $397 \mathrm{mg} \mathrm{kg}^{-1}$ in peeled peaches and between 376 and $609 \mathrm{mg} \mathrm{kg}^{-1}$ in unpeeled peaches. Cold storage at $4^{\circ} \mathrm{C}$ for 14 days or freezing and storing at $-12^{\circ} \mathrm{C}$ for 3 months produced no loss in TPs. Peaches stored at $30^{\circ} \mathrm{C}$ for $24 \mathrm{~h}$ resulted in a 1.7-fold increase in TPs. Studies of TPs in peaches processed at temperatures of $213^{\circ} \mathrm{F}$ for $40 \mathrm{~min}$, $220^{\circ} \mathrm{F}$ for $10 \mathrm{~min}$ and $230^{\circ} \mathrm{F}$ for $2.4 \mathrm{~min}$ indicate that processing above $213^{\circ} \mathrm{F}$ decreases levels of both TPs (up to $21 \%$ ) and procyanidins (up to $100 \%$ ). Processing at $213{ }^{\circ} \mathrm{F}$ for $40 \mathrm{~min}$ produced no significant loss in TPs. Furthermore, studies reveal that a 30-43\% loss in phenolic levels occurs during the first 3 months in storage after canning. It is clear that both storage and thermal processing conditions profoundly impact the levels of polyphenolics in peaches. More interestingly, these studies indicate that peaches are a rich source of procyanidins, having profiles similar to those found in cocoa, apples, wine and tea.
\end{abstract}

(C) 2002 Society of Chemical Industry

Keywords: peaches; procyanidins; phenolics; thermal processing; freezing; HPLC

\section{INTRODUCTION}

Clingstone peaches contain a wide array of complex secondary plant metabolites and polyphenolics. ${ }^{1}$ Phenolic plant metabolites are natural components of clingstone peaches that function in plant defence against insect and animal herbivory and oxidative damage. ${ }^{2-4}$ A growing body of evidence indicates that certain plant phenolics also play an important role in human health and disease prevention. ${ }^{5-8}$ Procyanidins are of particular interest owing to their potent antioxidant activity, ability to scavenge free radicals and nitrogen species ${ }^{9-12}$ and protective cardiovascular effects. ${ }^{13-15}$ Structurally, procyanidins are composed of the polyhydroxyl flavan-3-ol units $(+)$-catechin or $(-)$-epicatechin and exist in fruits and vegetables as monomers (Fig 1) and in more complex polymeric forms, such as when two monomers condense to form dimers as illustrated in Fig 2. Oligomeric procyanidins (polymers of the monomeric forms) demonstrate antioxidant activity that increases linearly with the number of reactive catechol and/or pyrogallol groups existing in the molecule. ${ }^{16,17}$ To date, little quantitative information is available on the procyanidin content of various fruits, and even less is know about how postharvest and processing conditions impact levels of procyanidins in foods. With the increased recognition of the role phenolics may play in human health, it has become increasingly more important to investigate the impact of postharvest and processing conditions on levels of total phenolics and procyanidins in foods.

The composition of phenolic constituents in fruits is impacted by both internal and external factors. These include genetic variation at the species and subspecies (cultivar) level, ${ }^{1,18-21}$ maturity at harvest, ${ }^{1,18,21,22}$ preharvest agromonic conditions ${ }^{23}$ and postharvest processing conditions. ${ }^{24,25}$ In addition, phenolic compounds are not uniformly distributed within the tissue of fruits. ${ }^{26}$ For example, at the subcellular level, phenolics are deposited in the cell wall and stored in vacuoles, whereas, at the tissue level, phenolics are concentrated in the epidermal and subepidermal layers

\footnotetext{
* Correspondence to: Alyson E Mitchell, Department of Food Science and Technology, Cruess Hall, University of California, One Shields Avenue, Davis, CA 95616, USA

E-mail: aemitchell@ucdavis.edu
}

(Received 10 April 2002; revised version received 9 July 2002; accepted 20 September 2002) 
<smiles>[R]C1([R2])[C@H](I)c2c(O)cc(O)cc2O[C@@H]1c1ccc(O)c(O)c1</smiles>

Catechin $\mathrm{R}_{1}=\mathrm{H}, \mathrm{R}_{2}=\mathrm{OH}$

Epicatechin $\mathrm{R}_{1}=\mathrm{OH}, \mathrm{R}_{2}=\mathrm{H}$

Figure 1. Representative structure of catechin and epicatechin.

of the fruit. ${ }^{26,27}$ As in the case of apples and grapes, the accumulation of low-molecular-weight phenolic compounds is greater in the outer tissues of peaches than in the inner tissues. ${ }^{28,29}$ Phenolic distribution is important with respect to the overall phenolic composition and antioxidant capacity of industrially processed foods. To date, few studies address the variations in phenolic composition of processed peaches, ${ }^{1,30,31}$ even though variations in phenolic composition can have profound impacts on the antioxidant capacity of processed peaches.

The harvest date for clingstone peaches is influenced both by the overall maturity of the fruit on the tree and by the availability of other fruit to the processor. Peaches are either hand or machine harvested and placed into wooden bins prior to processing. Clingstone peaches are typically processed within a few hours of harvesting in order to prevent softening and decay. Many companies have established a target time interval from harvest to process of 6-8h. Nevertheless, a number of factors may cause processors to either shorten or lengthen this time interval. Mechanical harvesting generally results in more damage to the fruit than hand harvesting, therefore accelerating the deterioration process. While hand-harvested peaches may be stored under refrigeration conditions for hours or days, mechanically harvested fruit must be processed quickly. However, even though certain peaches are given priority in the process schedule, they may remain in a receiving yard at temperatures of up to $40^{\circ} \mathrm{C}$ for hours before they are processed.

Clingstone peaches are most commonly preserved using thermal processing methods such as canning. Clingstones differ from freestone peaches in that they are considerably firmer in texture and, owing to a lack of the enzyme polygalacturonase, the stone clings to the flesh. Prior to canning, clingstone peaches are halved, pitted and peeled using lye (sodium hydroxide) to remove the thin skin. The use of heat in preservation of clingstone peaches assists in softening the texture to a degree that the fruit is acceptable to the consumer. The thermal process applied is greater than that required for microbiological destruction; in fact, the target is more related to texture modification.

This research addresses the influence of common postharvest processing practices on the levels of total phenolics in Ross clingstone peaches. Specific conditions assessed in these studies include the evaluation of lye-assisted peeling, freezing, cold storage $(-12$ and $\left.4{ }^{\circ} \mathrm{C}\right)$, short-term warm storage $\left(30^{\circ} \mathrm{C}\right), 6$ months of canned storage and the effects of three different timetemperature sterilisation processes on total phenolic activity. Additionally, we describe the profile of procyanidin oligomers in frozen clingstone and freestone peaches and assess the impact of thermal processing on procyanidins in Ross clingstone peaches. Studies addressing the impact of postharvest and processing conditions on total phenolics in processed foods are becoming more critical owing to the role plant-based phenolics may play in human health and disease<smiles>[R6][C@]1([2H])C(c2c(O)cc(O)c3c2O[C@@H](c2ccc(O)c(O)c2)[C@@]([R6])([2H])C3)c2ccc(O)cc2O[C@@H]1c1ccc(O)c(O)c1</smiles><smiles>Oc1cc(O)c2c(c1)OC1(c3ccc(O)c(O)c3)Oc3cc(O)c4c(c3[C@@H]1O2)O[C@H](c1ccc(O)c(O)c1)[C@H](O)C4</smiles>

Procyanidin $(4 \beta \rightarrow 8)$ Dimers

Figure 2. Representative structures of singly linked procyanidin B-type dimers and doubly linked procyanidin A-type dimers. 
prevention. Determining the relationships between postharvest and processing conditions and levels of phenolics in fruits is essential for understanding how to optimise and maintain levels of beneficial phenolics in commercially processed commodities.

\section{MATERIALS AND METHODS Chemicals}

Folin and Ciocalteau's phenol reagent and gallic acid were purchased from Sigma (St Louis, MO, USA). HPLC-grade acetone, methylene chloride, acetonitrile and acetic acid were obtained from Fisher Scientific (Houston, TX, USA). Reagent-grade, bacteria-free water was generated by a Barnstead (Dubuque, Iowa, USA) E-pure four-module deionisation system.

\section{Peaches}

Clingstone peaches of the Ross cultivar were hand picked from the University of California orchard (Winters, CA, USA). Fruits were harvested randomly from both the outer and internal canopy of selected trees in order to obtain a homogeneous sample. Following harvest, peaches were divided into four maturity classes, MI, MII, MIII and MIV, on the basis of external skin colour and firmness. ${ }^{32}$ Maturity class MIII peaches were stored at three different temperatures for different periods of time. One group of peaches was frozen at $-12^{\circ} \mathrm{C}$ for $0,1,2$ and 3 months to simulate frozen storage for analytical purposes. Another group was stored under refrigeration $\left(4^{\circ} \mathrm{C}\right)$ conditions for 0,7 and 14 days to mimic storage at a processor site prior to processing. A third group was stored at $30^{\circ} \mathrm{C}$ for $0,12,24$ and $48 \mathrm{~h}$ to simulate fruit waiting in bins in a receiving yard prior to processing.

\section{Extraction of total phenolics}

Phenolics were extracted from peach samples by homogenising peach material in an acetone/water/ acetic acid (70:29.5:0.05 v/v) extraction mixture. Specifically, pulverised samples $(6 \mathrm{~g}$ each) were spiked with $30 \mathrm{mg}$ of theobromine and pulse sonicated at $20 \mathrm{~min}$ intervals for $1 \mathrm{~h}$. Extracts were centrifuged at $3000 \mathrm{rpm}$ for $15 \mathrm{~min}$ at $20^{\circ} \mathrm{C}$ and resulting supernatants were filtered and concentrated using a rotary evaporator under partial vacuum at $40^{\circ} \mathrm{C}$. Concentrated samples were brought up to a total volume of $30 \mathrm{ml}$ and analysed for total phenolics. Procyanidin polymers were further extracted from samples using an additional solid phase extraction step on Supercosil Envi-18 $20 \mathrm{ml}$ SPE columns (Supelco, Inc, Bellefonte, PA, USA). The columns were preconditioned with 3 column volumes $(5 \mathrm{ml})$ of nanopure water, followed by 3 column volumes of methanol and 6 column volumes of nanopure water. Extracts were loaded onto the preconditioned SPE columns and washed with 10 column volumes $(5 \mathrm{ml})$ of nanopure water. The columns were then dried under vacuum for 1-2 min. Procyanidins were eluted from the SPE columns with
$10 \mathrm{ml}$ of an elution solvent containing acetone/water/ acetic acid $(70: 29.5: 0.5 \mathrm{v} / \mathrm{v})$.

\section{Measurement of total phenolics}

Total phenolics were analysed by the Folin-Ciocalteau assay. This reaction is based on the reduction of phosphomolybdic acid by phenols in aqueous alkali. The method determines the total free phenolic groups and is therefore a method to determine total soluble phenolics in a sample. Total phenolics were based upon gallic acid equivalents.

\section{HPLC analysis of procyanidins}

Procyanidin analysis was performed using a Waters 2690 Alliance HPLC system (Waters, Milford, MA, USA) according to established methods. ${ }^{33}$ Procyanidin oligomers were detected using a Waters 474 scanning fluorescence detector recording at excitation wavelength $276 \mathrm{~nm}$ and emission wavelength $316 \mathrm{~nm}$ and a Waters 996 PDA detector. Procyanidin oligomers were separated into oligomer classes, based upon their degree of polymerisation up to the decamer, using a Phenomenex (Torrance, CA, USA) $5 \mu \mathrm{m}$ Lichrosphere silica column $(250 \mathrm{~mm} \times 4.6 \mathrm{~mm})$. The binary mobile phase consisted of solvent A composed of methylene chloride/methanol/water/acetic acid $(82: 14: 2: 2 \mathrm{v} / \mathrm{v})$ and solvent $\mathrm{B}$ composed of methanol/ water/acetic acid (96:2:2 v/v). Separations were performed by linear gradients of $\mathrm{B}$ in $\mathrm{A}$ at a flow rate of $1 \mathrm{ml} \mathrm{min}-1$ as follows: $0-30 \mathrm{~min}, 0-17.6 \% \mathrm{~B}$ in $\mathrm{A}$; $30-45 \mathrm{~min}, 17.6-30.7 \% \mathrm{~B}$ in $\mathrm{A} ; 45-50 \mathrm{~min}, 30.7-$ $87.8 \% \mathrm{~B}$ in $\mathrm{A}$. In all cases the columns were reequilibrated between injections with the equivalent of $25 \mathrm{ml}$ (10 column volumes) of the initial mobile phase. All samples were run in triplicate.

\section{Determination of recovery}

Theobromine was used as an internal standard. Extraction recoveries were determined using standard spike and recovery techniques. Briefly, a known amount of theobromine was added to samples prior to extraction. Recoveries of theobromine were determined using a standard curve based upon HPLC peak areas of a set of known theobromine standards generated using the same conditions as for procyanidin (PC) sample analysis (see below). Linear calibration curves $\left(r^{2}>0.995\right)$ were obtained in the range of $0.1-5 \mathrm{mg} \mathrm{ml}^{-1}$.

\section{Relative quantitation and spectral identification of individual PCs}

PC oligomers were identified by comparing PDA spectra, fluorescence spectra and $t_{\mathrm{R}}$ with those corresponding to PC oligomer standards isolated from cocoa $^{34}$ Isomeric forms of PC oligomers were grouped according to their degree of polymerisation. Peak areas for each isomer group were summed and compared with the summed area of isomers corresponding to PC oligomers within the standard. The 
combined peak area of each oligomer set was normalised to the peak area for the theobromine standard.

\section{Peach processing and commercial sterilisation conditions}

Peaches were sorted by maturity and processed by experienced personnel in the Food Processing Laboratory of the University of California, Davis. Prior to canning, peaches were sliced, pitted and peeled with $2 \%$ lye, rinsed and packed into number $2 \frac{1}{2}$ cans. Cans were made with enamel-coated bodies and tin-plated lids. Filled cans were weighed and the peach content was adjusted to $19 \mathrm{oz}$ of fruit per can. Cans were filled with $11.5 \mathrm{oz}$ of $30^{\circ}$ Brix syrup prior to pulling a vacuum on the pack and seaming the lids to the cans. Processing conditions were designed to ensure commercial sterility, and similar temperature $\left({ }^{\circ} \mathrm{F}\right)$ values were chosen for the three processes. Fruit was processed in a Food Manufacturing Corp Steritort (Madera, CA, USA). Conditions tested were $213^{\circ} \mathrm{F}$ for $40 \mathrm{~min}$, $220^{\circ} \mathrm{F}$ for $10 \mathrm{~min}$ and $230^{\circ} \mathrm{F}$ for $2.4 \mathrm{~min}$. All three processes were started with a $3 \mathrm{~min}$ come-up time to evacuate air from the Steritort chamber and to bring the cans up to temperature. All cans were cooled with ambient-temperature water for $10 \mathrm{~min}$ after processing.

\section{RESULTS AND DISCUSSION}

The impact of maturation on total phenolics in peaches was assessed in Ross clingstone peaches harvested from the same field and sorted into one of four maturity classes, MI, MII, MIII or MIV, based upon visual inspection of the fruit and comparison with colour standards. ${ }^{32}$ Although phenolic levels were measured in all maturity classifications, the primary interest was in MIII peaches, as this grade is most commonly used in the canning process. Total phenolics were measured in both peeled and unpeeled fruit. Phenolic levels ranged between 316 and $397 \mathrm{mg}$ $\mathrm{kg}^{-1}$ in peeled fruit and between 376 and $609 \mathrm{mg} \mathrm{kg}^{-1}$ in unpeeled fruit (Table 1). On average, unpeeled fruit contained 1.5-fold higher levels of phenolics than peeled fruit. Levels of phenolics were statistically highest $(P>0.05)$ in unpeeled fruit of maturity classes

Table 1. Effect of fruit maturity level on concentrations of total phenolics ( $\mathrm{mg} \mathrm{kg}^{-1}$ fresh weight) in Ross clingstone peaches

\begin{tabular}{llr}
\hline \multirow{2}{*}{ Maturity class } & \multicolumn{2}{c}{ Total phenolics $\left(\mathrm{mg} \mathrm{kg}^{-1}\right)^{\mathrm{a}, \mathrm{b}}$} \\
\cline { 2 - 3 } MI & Peeled & Unpeeled \\
MII & $316 \pm 19.2 \mathrm{a}$ & $609 \pm 39.4 \mathrm{a}$ \\
MIII & $397 \pm 18.3 \mathrm{~b}$ & $569 \pm 39.3 \mathrm{~b}$ \\
MIV & $326 \pm 8.5 \mathrm{a}$ & $376 \pm 25.8 \mathrm{c}$ \\
\hline
\end{tabular}

\footnotetext{
a Results presented as mean $\pm \mathrm{SD}$ for triplicates. Maximum relative SD is $6.9 \%$.

b Means followed by a different letter within a column are significantly different $(P<0.05)$.
}

Table 2. Effect of peel removal method on concentrations of total phenolics ( $\mathrm{mg} \mathrm{kg}^{-1}$ fresh weight) in Ross clingstone peaches

\begin{tabular}{|c|c|}
\hline Peeling method & Total phenolics $\left(m g \mathrm{~kg}^{-1}\right)^{\mathrm{a}, \mathrm{b}}$ \\
\hline Lye-assisted & $274 \pm 10.7 a$ \\
\hline Manual & $347 \pm 24.0 b$ \\
\hline Unpeeled & $537 \pm 10.0 c$ \\
\hline \multicolumn{2}{|c|}{$\begin{array}{l}{ }^{a} \text { Results presented as mean } \pm \text { SD for triplicates. Maxi- } \\
\text { mum relative } S D \text { is } 6.9 \% \text {. } \\
\text { b Means followed by a different letter are significantly } \\
\text { different }(P<0.05) \text {. }\end{array}$} \\
\hline
\end{tabular}

MI and MII. This result is not surprising, as the peel is a primary location for phenolic species, and younger fruit has a higher surface-to-flesh ratio than older fruit. Levels of total phenolics in unprocessed MIII peaches were $326 \pm 8.5 \mathrm{mg} \mathrm{kg}^{-1}$ for peeled fruit and $376 \pm$ $25.8 \mathrm{mg} \mathrm{kg}^{-1}$ for unpeeled fruit. Because most peaches undergo lye-assisted peeling prior to processing, we assessed the impact of lye-assisted peeling ( $2 \%$ lye solution) on levels of total phenolics in MIII fruit. These results indicated that manual peeling results in a 1.3-fold higher retention of total phenolics than lyeassisted peeling (Table 2). It is known that the use of lye results in damage to cells and increases the degradation of phenolic compounds in fruit.

The impact of several postharvest storage conditions on levels of total phenolics (TPs) in MIII peaches was also investigated. To evaluate the impact of freezing and frozen storage on total phenolic levels, a group of randomly selected MIII peaches were peeled, pitted, sliced, frozen and stored at $-12^{\circ} \mathrm{C}$ for a period of 3 months. Total phenolic levels were measured in these

Table 3. Effects of storage at $-12,4$ and $30^{\circ} \mathrm{C}$ on concentrations of total phenolics $\left(\mathrm{mg} \mathrm{kg}^{-1}\right.$ fresh weight) in Ross clingstone peaches

\begin{tabular}{lcc}
\hline & \multicolumn{2}{c}{ Total phenolics $\left(\mathrm{mg} \mathrm{kg}^{-1}\right)^{\mathrm{a}, \mathrm{b}}$} \\
\cline { 2 - 3 } Time & \multicolumn{1}{c}{ Peeled } & Unpeeled \\
\hline Stored at $-12^{\circ} \mathrm{C}$ & \\
O months & $423 \pm 9.0 \mathrm{a}$ & $501 \pm 16.0 \mathrm{a}$ \\
1 month & $643 \pm 6.7 \mathrm{~b}$ & $717 \pm 25.3 \mathrm{~b}$ \\
2 months & $457 \pm 7.9 \mathrm{c}$ & $591 \pm 13.2 \mathrm{c}$ \\
3 months & $500 \pm 19.8 \mathrm{~d}$ & $526 \pm 13.5 \mathrm{a}$ \\
Stored at $4^{\circ} \mathrm{C}$ & \\
O days & $398 \pm 8.5 \mathrm{a}$ & $468 \pm 4.2 \mathrm{a}$ \\
7 days & $385 \pm 1.6 \mathrm{ab}$ & $439 \pm 7.0 \mathrm{~b}$ \\
14 days & $378 \pm 6.4 \mathrm{~b}$ & $443 \pm 9.0 \mathrm{~b}$ \\
Stored at $30^{\circ} \mathrm{C}$ & \\
Oh & $427 \pm 11.0 \mathrm{a}$ & $515 \pm 23.2 \mathrm{a}$ \\
12h & $601 \pm 9.4 \mathrm{~b}$ & $698 \pm 5.1 \mathrm{~b}$ \\
$24 \mathrm{~h}$ & $721 \pm 2.8 \mathrm{c}$ & $785 \pm 6.2 \mathrm{c}$ \\
$48 \mathrm{~h}$ & $643 \pm 13.4 \mathrm{~d}$ & $736 \pm 14.2 \mathrm{~d}$ \\
\hline
\end{tabular}

a Results presented as mean $\pm \mathrm{SD}$ for triplicates. Maximum relative SDs are $3.9,2.1$ and $4.5 \%$ respectively.

${ }^{b}$ Means followed by a different letter within a column are significantly different $(P<0.05)$. 
samples at time 0,1, 2 and 3 months (Table 3 ). These data indicate that storage of peeled peaches at $-12{ }^{\circ} \mathrm{C}$ results in a statistically significant increase $(P<0.05)$ in TP activity, as compared with fresh peach, over a 3 month period. Unpeeled peaches demonstrated a statistically significant increase $(P<0.05)$ in TPs at 1 and 2 months. However, we believe that the levels of TPs in the samples taken at the 1 month time period are artificially high owing to an error in non-biased sampling. Specifically, these samples had a significantly greater proportion of flesh surrounding the seed incorporated into them. This area of the peach contains high levels of TPs in comparison with the flesh closer to the surface and therefore resulted in artificially high measures of TPs. Sampling errors were corrected in months 2 and 3. It appears that the increase in TPs occurred as a result of the freezing process, but that TP levels were most likely constant during the storage periods. The freezing process may result in disruption of the cellular matrix and more facilitated extraction of the phenolics.

To investigate the impact of cold storage on TP levels, MIII peaches were stored at $4{ }^{\circ} \mathrm{C}$ for a period of 14 days. TP levels were measured in peeled and unpeeled fruit on days 0,7 and 14. These results indicate that cold storage of peaches for 14 days resulted in no loss in TP activity in either the peeled or unpeeled fruit (Table 3 ) as compared with fresh peach. In fact, a small increase $(P<0.05)$ in TP levels was observed on day 14 in peeled fruit and on days 7 and 14 in unpeeled fruit. One possible explanation for the small increases in TPs observed during cold storage may be that the fruit lost moisture to the environment, and this slight dehydration resulted in a relative increase in the phenolics present. The impact of short-term above-room-temperature $\left(30^{\circ} \mathrm{C}\right)$ storage on TP levels was also investigated in this study. Peaches were stored in a climate-controlled temperature room at $30^{\circ} \mathrm{C}$ for a period of $48 \mathrm{~h}$. TPs were measured at times $0,12,24$ and $48 \mathrm{~h}$. Storage of peaches for $24 \mathrm{~h}$ at $30^{\circ} \mathrm{C}$ resulted in a $69 \%$ increase in TPs in peeled fruit and a $36 \%$ increase in unpeeled fruit (Table 3). Levels of total phenolics began to decline after $24 \mathrm{~h}$, with levels of total phenolics $50 \%$ higher than initial levels in peeled fruit and $28 \%$ higher in unpeeled fruit at $48 \mathrm{~h}$. Stresses to fruit tissue, in the form of either insect attack or cellular damage due to peeling, are known to result in activation of enzymes such as phenylalanine ammonia lyase (PAL), which catalyses the synthesis of phenolic compounds. In addition, enzymes are most active at temperatures above room temperature $\left(30-50{ }^{\circ} \mathrm{C}\right)$; therefore PALcatalysed phenolic synthesis would cause levels in peeled fruit to be higher than in unpeeled fruit. Polyphenol oxidase, which catalyses oxidation and polymerisation of phenolics, may also be quite active during the $48 \mathrm{~h}$ storage period at $30^{\circ} \mathrm{C}$ used in this study. Polymerised phenolics may not be identified in the assay used in this study, which may explain the apparent decrease in concentration after $24 \mathrm{~h}$.
Clingstone peaches are typically thermally processed using conditions that ensure commercial sterility, defined as the absence of micro-organisms of public health significance, under normal conditions of transportation and storage. Typical canning conditions involve heat sterilisation at $220^{\circ} \mathrm{F}$ for $10 \mathrm{~min}$. To date, little is known of how thermal processing impacts phenolics. However, it has been shown that thermal processing may result in polymerisation of phenolics. ${ }^{35}$ It is not clear whether polymerised phenolics have the same biological activity as lower-molecular-weight phenols, and at what specific size their effectiveness as antioxidants declines. Indeed, very little is known about the phenolic profiles of both raw and processed clingstone peaches. To assess these issues, we tested the impact of three different time-temperature heat sterilisation conditions on levels of TPs in MIII peaches. Conditions tested were $213^{\circ} \mathrm{F}$ for $40 \mathrm{~min}$, $220^{\circ} \mathrm{F}$ for $10 \mathrm{~min}$ and $230^{\circ} \mathrm{F}$ for $2.4 \mathrm{~min}$. Thermal processing of peaches at $220^{\circ} \mathrm{F}$ for $10 \mathrm{~min}$ resulted in a $21 \%$ loss in total phenolics, a temperature of $230^{\circ} \mathrm{F}$ for $2.4 \mathrm{~min}$ resulted in an $11 \%$ loss in total phenolics, whereas a temperature of $213^{\circ} \mathrm{F}$ for $40 \mathrm{~min}$ produced no significant loss in total phenolics as compared with raw material (Table 4). While it may be possible to prevent loss of phenolics by using lower temperatures during the canning process, our results indicate that dramatic changes in the phenolic levels also occur in the cans stored at room temperature during the first 3 months (Table 4). For example, storing canned peaches at room temperature during the first 3 month period results in a $30-43 \%$ loss in total phenolics in all samples $(P<0.05)$. Total phenolic levels increased slightly between the 3 and 6 month period in fruit processed above $213^{\circ} \mathrm{F}$, whereas fruit processed at $213^{\circ} \mathrm{F}$ for $40 \mathrm{~min}$ demonstrated a significant reduction in TPs between the 3 and 6 month period $(P<0.05)$. It may be that the phenolics present after initial canning serve as antioxidants during the storage period and are themselves consumed during the initial 3 months. The cans used in this study had enamelcoated bodies with tin-plated lids. Tin can serve as an antioxidant; therefore, if tin-plated bodies were used, there may have been less phenolic oxidation. Further

\begin{tabular}{|c|c|c|c|}
\hline \multirow{2}{*}{$\begin{array}{l}\text { Time } \\
\text { (months) }\end{array}$} & \multicolumn{3}{|c|}{ Total phenolics (mg kg $\left.{ }^{-1}\right)^{a, b, c}$} \\
\hline & $213^{\circ} \mathrm{F}$ & $220^{\circ} \mathrm{F}$ & $230^{\circ} \mathrm{F}$ \\
\hline 0 & $398 \pm 6.3 a$ & $314 \pm 12.3 b$ & $353 \pm 14.6 c$ \\
\hline 3 & $230 \pm 3.3 a$ & $221 \pm 9.7 a b$ & $204 \pm 9.9 b$ \\
\hline 6 & $220 \pm 4.8 a$ & $247 \pm 0.4 b$ & $233 \pm 2.2 c$ \\
\hline
\end{tabular}

a Results presented as mean \pm SD for triplicates. Maximum relative SD is $4.9 \%$.

b Means followed by a different letter within a row are significantly different $(P<0.05)$.

c Significant differences $(P<0.05)$ were found among the three means within each column. 

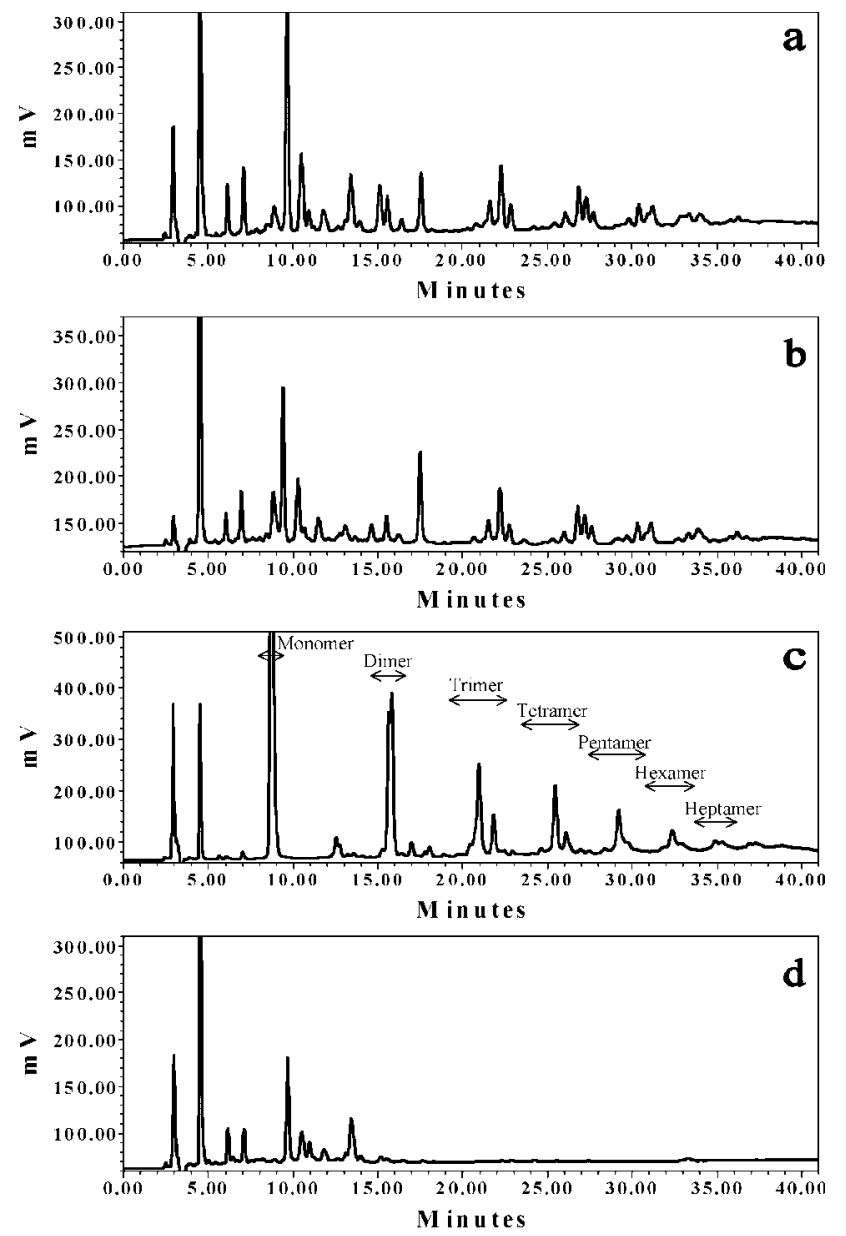

Figure 3. Normal phase high-performance liquid chromatograms of procyanidin oligomers in (a) frozen freestone peaches, (b) frozen clingstone peaches, (c) defatted cocoa extract and (d) canned clingstone peaches monitored by fluorescence detection.

studies investigating the impact of long-term storage of thermally processed peaches are currently under way in our laboratory.

The levels and degree of polymerisation of procyanidin oligomers were characterised in frozen and thermally processed clingstone peaches. HPLC profiles indicate that both clingstone and freestone peaches contain substantial amounts of procyanidin oligomers ranging from monomer through heptamer (Figs 3(a) and 3(b)). The procyanidin profile obtained in peaches is similar to profiles found in grapes, cocoa and beverages linked to health benefits, such as tea and wine. Fig 3(c) is the chromatogram of the procyanidin profile found in cocoa and demonstrates the similarities between the procyanidin profile found in peaches and that found in cocoa. ${ }^{33,34}$ Given the tremendous body of research correlating the consumption of foods rich in procyanidins (eg tea, red wine and apples) with a reduced risk of cardiovascular disease, our current findings suggest that peaches may be an important source of dietary procyanidins. Fig $3(d)$ is the procyanidin profile of Ross clingstone peaches after thermal processing at $220^{\circ} \mathrm{F}$ for $10 \mathrm{~min}$. A comparison of the procyanidin oligomer profile in frozen peaches (Fig 3(a)) and that in peaches processed at $220^{\circ} \mathrm{F}$ for $10 \mathrm{~min}(\mathrm{Fig} \mathrm{3(d)})$ demonstrates a profound reduction in procyanidins in canned peaches relative to frozen peaches. The profile of procyanidins in canned freestone peaches was not determined in this study. The flavonoid profile in canned freestone cultivars may differ from that in clingstone cultivars, as freestone cultivars contain higher levels of leucoanthocyanins than clingstone cultivars. Fig 4 presents the summed and normalised areas of individual procyanidin oligomers in frozen and thermally processed peaches. As can be seen in this figure, there is a $49 \%$ reduction in procyanidin monomers, an $88 \%$ reduction in procyanidin dimers and a complete loss of procyanidin oligomer trimers through heptamers in the thermally processed peaches.

\section{CONCLUSIONS}

The research described in this paper demonstrates that there are complex relationships between postharvest and processing conditions and levels of total phenolics in clingstone peaches. Studies clearly indicate that freezing and cold storage have relatively little impact on TPs and procyanidins, whereas lye-assisted peeling and canning using temperatures typically employed in commercial sterilisation have detrimental impacts on
Figure 4. Comparison of individual procyanidin oligomers in frozen (white) and canned (shaded) clingstone peaches. An asterisk denotes a significant difference $(P<0.05)$ between frozen and canned procyanidin levels. Results are presented as mean \pm SD for triplicates.

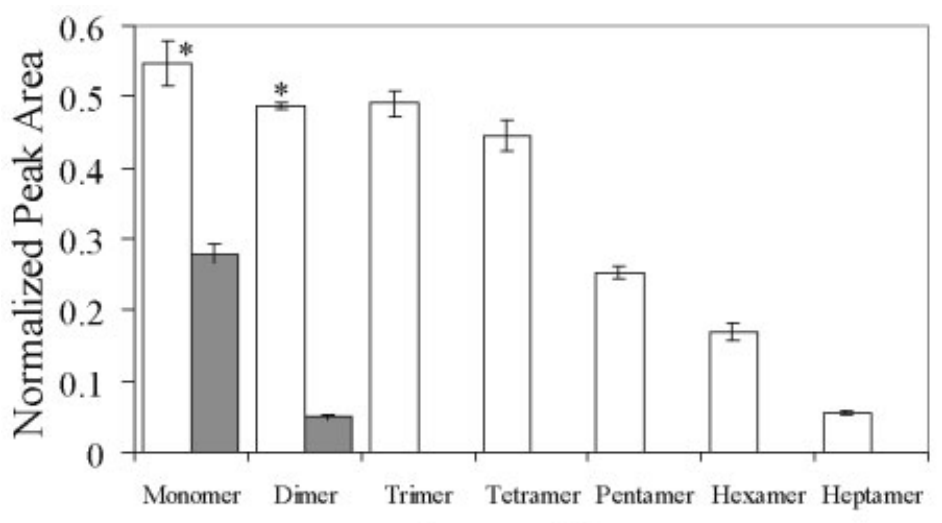

Procyanidins 
both TP and procyanidin levels. Interestingly, we found that levels of TPs could be increased up to 1.7fold by simply holding peaches at $30^{\circ} \mathrm{C}$ for $24 \mathrm{~h}$. However, it is still unclear if increases in TPs are due to increased production of TPs or increased extractability of TPs, and more experimentation is needed to resolve this question. Additionally, the question of which individual phenolic(s) are responsible for the increase in TPs needs to be addressed, as individual phenolics have various biological activities and may impart changes in flavour and colour of the peach.

While these studies indicate that it may be possible to prevent losses of TPs and procyanidins by using lower temperatures during the canning process, dramatic reductions in TPs occur in the first 3 months of canned storage. It may be that the phenolics present after canning serve as antioxidants during the initial storage period and are themselves consumed. A possible strategy for decreasing the impact of thermal processing on levels of phenolics may be the use of tin-plated cans, since tin can serve as an antioxidant. Further studies investigating relationships between postharvest processing conditions and levels of specific phenolics, in particular the procyanidins, are currently in progress in our laboratory.

\section{ACKNOWLEDGEMENTS}

The authors would like to thank Dr Tom Gadziel of the Department of Pomology at UC Davis for his help and advice in harvesting and sorting peaches, and Robert Marquardt, Manager of the UC Davis Food Science and Technology Pilot Plant, for his invaluable assistance and advice during thermal processing of peaches.

\section{REFERENCES}

1 Chang S, Tan C, Frankel EN and Barrett DM, Low-density lipoprotein antioxidant activity of phenolic compounds and polyphenol oxidase activity in selected clingstone peach cultivars. J Agric Food Chem 48:147-151 (2000).

2 Stevenson PC, Anderson JC, Blaney WM and Simmonds MSJ, Developmental inhibition of Spodoptera litura (Fab) larvae by a novel caffeoylquinic acid from the wild groundnut, Arachis paraguariensis. F Chem Ecol 19:2917-2933 (1993).

3 Duval B, Shetty K and Thomas WH, Phenolic compounds and antioxidant properties in the snow alga Chlamydomonas nivalis after exposure to UV light. F Appl Phycol 11:559-566 (1999).

4 Kwok D and Shetty K, Pseudomonas spp-mediated regulation of total phenolic and rosmarinic acid levels in shoot-based clonal lines of thyme (Thymus vulgaris L). F Food Biochem 20:365-377 (1997).

5 Block G, Patterson B and Subar A, Fruit, vegetables and cancer prevention: a review of the epidemiological evidence. Nutr Cancer 18:1-29 (1992).

6 Hertog M, Feskens EJM, Hollman PCH, Katan MB and Kromhout D, Dietary antioxidant flavonoids and risk of coronary heart disease: the Zuptphen Elderly Study. Lancet 342:1007-1011 (1993).

7 Hertog M, Feskens EJM, Hollman PCH, Katan MB and Kromhout D, Intake of potentially anticarcinogenic flavonoids and their determinants in adults in the Netherlands. Nutr Cancer 20:21-29 (1993).
8 Ness AR and Powles JW, Fruits and vegetables and cardiovascular disease: a review. Int $\mathcal{F}$ Epidemiol 26:1-13 (1997).

9 Hagerman AE, Riedel KM, Jones GA, Sovik KN, Ritchard NT, Hartzfeld PW and Riechel TL, High molecular weight plant polyphenolics (tannins) as biological antioxidants. 7 Agric Food Chem 46:1887-1892 (1998).

10 Ariga $T$ and Hamano $M$, Radical scavenging action and its mode in procyanidins B-1 and B-3 from azuki beans to peroxyl radicals. Agric Biol Chem 54:2499-2504 (1990).

11 Arpentine G, Fernandez Y, Bourzeix M and Mitjavila S, Relation between the structure of a series of procyanidins and their radical superoxide scavenger capacity. Proc Group Polyphenols 16:237-240 (1992).

12 Arteel GE and Sies H, Protection against peroxynitrite by cocoa polyphenolic oligomers. FEBS Lett 462:167-170 (1999).

13 Teissedre PL, Frankel EN, Waterhouse AL, Peleg $\mathrm{H}$ and German JL, Inhibition of in vitro human LDL oxidation by polyphenolics from grapes and wines. $\mathcal{F}$ Agric Food Chem 70:55-61 (1996).

14 Mangiapane H, Thomson J, Salter A, Brown S, Bell SD and White DA, The inhibition of the oxidation of low density lipoprotein by $(+)$-catechin, a naturally occurring flavonoid. Biochem Pharmacol 43:445-450 (1992).

15 Rein D, Paglieroni TG, Peason DA, Wun T, Schmitz HH, Gosselin R and Keen CL, Cocoa and wine polyphenols modulate platelet activation and function. F Nutr 130:2120S2126S (2000).

16 Rice-Evans CA, Miller NJ and Paganga G, Structure-antioxidant activity relationships of flavonoids and phenolic acid. Free Rad Biol Med 20:933-956 (1996).

17 Lotito SB, Actis-Goretta L, Renart ML, Caligiuri M, Rein D, Schmitz HH, Steinberg FM, Keen CL and Fraga CG, Influence of oligomer chain length on the antioxidant activity of procyanidins. Biochem Biophys Res Commun 276:945-951 (2000).

18 Kabuto N, Mimura $\mathrm{H}$ and Shimamura $\mathrm{K}$, Differences in phenolic levels among mature peach and nectarine cultivars and their relation to astringency. $\mathcal{F}$ fpn Soc Hort Sci 69:35-39 (2000).

19 Tomás-Barberán FA, Gil MI, Cremin P, Waterhouse AL, HessPierce B and Kader AA, HPLC-DAD-ESIMS analysis of phenolic compounds in nectarines, peaches, and plums. $\mathcal{F}$ Agric Food Chem 49:4748-4760 (2001).

20 Amiot M, Tacchini M, Aubert SY and Oleszek W, Influence of cultivar, maturity stage, and storage conditions on phenolic composition and enzymatic browning of pear fruits. $\mathcal{F}$ Agric Food Chem 43:1132-113? (1995).

21 Bostock RM, Wilcox SM, Wang G and Adaskaveg JE, Suppression of Monilinia fructicola cutinase production by peach fruit surface phenolic acids. Physiol Mol Plant Pathol 54:37-50 (1999).

22 Lee CY, Kagan V, Jaworski AW and Brown SK, Enzymatic browning in relation to phenolic compounds and PPO activity among various peach cultivars. F Agric Food Chem 38:99-101 (1990).

23 McClure JW, Physiological functions of flavonoids, in The Flavonoids, Ed by Harborne JB, Mabry TJ and Mabry H, Chapman and Hall, London, pp 970-1055 (1975).

24 Connor AM, Luby JJ, Hancock JF, Berkheimer S and Hanson EJ, Changes in fruit antioxidant activity among blueberry cultivars during cold-temperature storage. 7 Agric Food Chem 50:893-898 (2002).

25 Tomas-Barberan FA and Espin JC, Phenolic compounds and related enzymes as determinants of quality in fruits and vegetables. F Agric Food Chem 81:853-876 (2001).

26 Macheix JJ, Fleuriet A and Billot J, in Fruit Phenolics, Ed by Macheix JJ, Fleuriet A and Billot J, CRC Press, Boca Raton, FL Chap 3, pp 149-238 (1990).

27 Ibrahim R and Barron D, Phenylpropanoids, in Methods in Plant Biochemistry, Vol 1, Ed by Dey PM and Harborne JB, Academic Press, London, pp 75-111 (1989). 
28 Perez-Ilzarbe FJ, Hernandez T and Estrella I, Phenolic compounds in apples: varietal differences. $Z$ Lebensm Untersuch Forsch 192:551-554 (1991).

29 Fernandez de Simon B, Hernandez T and Estrella I, Phenolic composition of white grapes (var Airen). Changes during ripening. Food Chem 47:1531-1535 (1993).

30 Bengoechea ML, Sancho AI, Bartolome B, Estrella I, GomezCordoves $\mathrm{C}$ and Hernandez $\mathrm{T}$, Phenolic composition of industrially manufactured purees and concentrates from peach and apple fruits. F Agric Food Chem 45:4071-4075 (1997).

31 Talcott ST, Howard LR and Brenes CH, Contribution of periderm material and blanching time to the quality of pasteurized peach puree. F Agric Food Chem 48:4590-4596 (2000).

32 Tourjee KR, Barrett DM, Romero MV and Gradziel TV, Measuring flesh color variability among processing clingstone peach genotypes differing in carotenoid composition. $\mathcal{f} \mathrm{Am} \mathrm{Soc}$ Hort Sci 123:433-437 (1998).

33 Hammerstone JF, Lazarus SA, Mitchell AE, Rucker RB and Schmitz HH, Identification of procyanidins in cocoa (Theobroma cacao) and chocolate using high-performance liquid chromatography/mass spectrometry. If Agric Food Chem 47:490-496 (1999).

34 Adamson GE, Lazarus SA, Mitchell AE, Prior RL, Cao G, Jacobs PH, Kremers BG, Hammerstone JF, Rucker RB, Ritter KA and Schmitz HH, HPLC method for the quantification of procyanidins in cocoa and chocolate samples and correlation to total antioxidant capacity. F Agric Food Chem 47:4184-4188 (1999).

35 Howard LR, Braswell DD and Aselage J, Chemical composition and color of strained carrots as affected by processing. $\mathcal{F}$ Food Sci 61:327-330 (1996). 